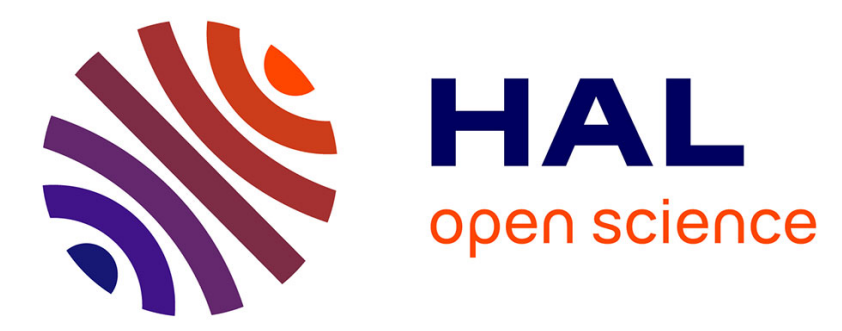

\title{
Disease spread in small-size directed networks: Epidemic threshold, correlation between links to and from nodes, and clustering
}

\author{
Mathieu Moslonka-Lefebvre, Marco Pautasso, Mike J. Jeger
}

\section{To cite this version:}

Mathieu Moslonka-Lefebvre, Marco Pautasso, Mike J. Jeger. Disease spread in small-size directed networks: Epidemic threshold, correlation between links to and from nodes, and clustering. Journal of Theoretical Biology, 2009, 260 (3), pp.402. 10.1016/j.jtbi.2009.06.015 . hal-00554629

\author{
HAL Id: hal-00554629 \\ https://hal.science/hal-00554629
}

Submitted on 11 Jan 2011

HAL is a multi-disciplinary open access archive for the deposit and dissemination of scientific research documents, whether they are published or not. The documents may come from teaching and research institutions in France or abroad, or from public or private research centers.
L'archive ouverte pluridisciplinaire HAL, est destinée au dépôt et à la diffusion de documents scientifiques de niveau recherche, publiés ou non, émanant des établissements d'enseignement et de recherche français ou étrangers, des laboratoires publics ou privés. 


\section{Author's Accepted Manuscript}

Disease spread in small-size directed networks: Epidemic threshold, correlation between links to and from nodes, and clustering

Mathieu Moslonka-Lefebvre, Marco Pautasso, Mike J. Jeger

PII: S0022-5193(09)00267-7

DOI: doi:10.1016/j.jtbi.2009.06.015

Reference: YJTBI 5597

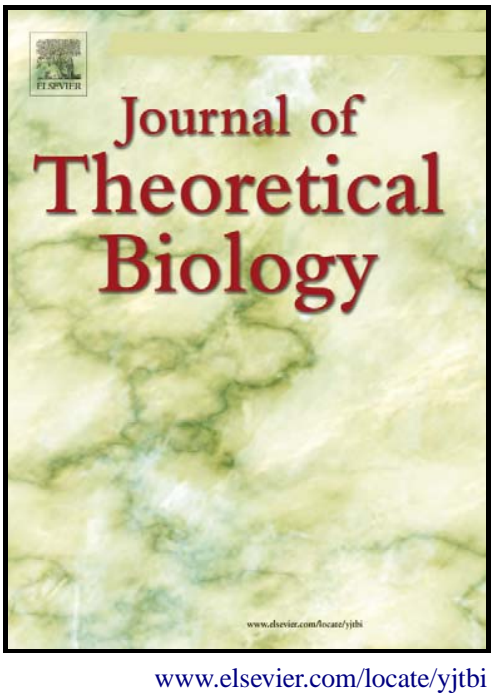

To appear in: $\quad$ Journal of Theoretical Biology

Received date: 13 January 2009

Revised date: $\quad 15$ April 2009

Accepted date: $\quad 7$ June 2009

Cite this article as: Mathieu Moslonka-Lefebvre, Marco Pautasso and Mike J. Jeger, Disease spread in small-size directed networks: Epidemic threshold, correlation between links to and from nodes, and clustering, Journal of Theoretical Biology, doi:10.1016/j.jtbi.2009.06.015

This is a PDF file of an unedited manuscript that has been accepted for publication. As a service to our customers we are providing this early version of the manuscript. The manuscript will undergo copyediting, typesetting, and review of the resulting galley proof before it is published in its final citable form. Please note that during the production process errors may be discovered which could affect the content, and all legal disclaimers that apply to the journal pertain. 
1 Disease spread in small-size directed networks: epidemic

2 threshold, correlation between links to and from nodes, and

3 clustering

4

5 Mathieu Moslonka-Lefebvre' $1,2,3$, Marco Pautasso ${ }^{3^{*}}, \&$ Mike J. Jeger ${ }^{3}$

6

71 Department of Biology, Université Paris-Sud XI, 91405 Orsay, France

82 Biochemistry and Bio-engineering Department, ENS Cachan, 61 av President Wilson,

994230 Cachan, France

103 Division of Biology, Imperial College London, Silwood Park, Ascot, SL5 7PY, UK

11 *correspondence: m.pautasso@ic.ac.uk, ++44 02075942533

12

13 Revised for: Journal of Theoretical Biology

14 Running head: Threshold, in- and out-degree, and clustering 15

16 Word Count: $\sim 4,000$

17 Five tables, four figures 
Abstract

19 Network epidemiology has mainly focused on large-scale complex networks. It is unclear 20 whether findings of these investigations also apply to networks of small size. This

21 knowledge gap is of relevance for many biological applications, including meta-

22 communities, plant-pollinator interactions and the spread of the oomycete pathogen

23 Phytophthora ramorum in networks of plant nurseries. Moreover, many small-size biological

24 networks are inherently asymmetrical and thus cannot be realistically modelled with

25 undirected networks. We modelled disease spread and establishment in directed networks

26 of 100 and 500 nodes at four levels of connectance in six network structures (local, small-

27 world, random, one-way, uncorrelated and two-way scale-free networks). The model was

28 based on the probability of infection persistence in a node and of infection transmission

29 between connected nodes. Regardless of the size of the network, the epidemic threshold

30 did not depend on the starting node of infection but was negatively related to the

31 correlation coefficient between in- and out-degree for all structures, unless networks were

32 sparsely connected. In this case clustering played a significant role. For small-size scale-free

33 directed networks to have a lower epidemic threshold than other network structures, there

34 needs to be a positive correlation between number of links to and from nodes. When this

35 correlation is negative (one-way scale-free networks), the epidemic threshold for small-size

36 networks can be higher than in non scale-free networks. Clustering does not necessarily

37 have an influence on the epidemic threshold if connectance is kept constant. Analyses of

38 the influence of the clustering on the epidemic threshold in directed networks can also be

39 spurious if they do not consider simultaneously the effect of the correlation coefficient

40 between in- and out-degree.

42 Keywords

43 Commercial transport, disease management, food webs, initial conditions, spread of ideas, 44 Susceptible-Infected-Susceptible (SIS) 


\section{Introduction}

47 Epidemic models assuming regularly or randomly connected individuals are now involving more complex networks (Keeling, 2005; May, 2006; Jeger et al., 2007). Compared to regular lattices, epidemics in small-world networks are facilitated by long-distance connections (Moore and Newman, 2000). In scale-free networks of infinite size, epidemics lack a threshold, which implies that even pathogens with a low probability of transmission will persist (Pastor-Satorras and Vespignani, 2001). Whether these findings also apply to complex networks of small size is still unclear. This is an important knowledge gap as small-size networks are relevant to many epidemics spreading within subgroups of individuals (Liu et al., 2004; Guimarães et al., 2007; Sun and Gao, 2007; Pellis et al., 2009).

Networks are not only relevant for epidemiology but have found application in a variety of biological systems (Proulx et al., 2005; Bascompte, 2007; Jeger et al., 2007). Networks with size of the order of magnitude of hundreds of nodes, in turn, are relevant for many current issues in ecology. Examples include closely interacting primate groups (Dunbar, 1993), social networks of manakins (Ryder et al., 2008), cavity-nesting community webs (Blanc and Walters, 2007), diseases of bumble bee colonies (Otterstatter and Thomson, 2007) and vascular epiphytes on host tree species (Lobel et al., 2006; Burns, 2007). The importance of small-size networks in biology is further shown by plant-pollinator interactions (e.g. Olesen et al., 2006; Nielsen and Bascompte, 2007), mycorrhiza, rhizomorphs and plant pathosystems (Southworth et al., 2005; Lamour et al. 2007; Brooks et al., 2008), and food webs (e.g. Montoya and Solé, 2002; Neutel et al., 2007).

Although networks of small size are relevant both for epidemiology and for ecology and evolution (e.g. Hanski and Ovaskainen, 2000; Brooks, 2006; Ings et al., 2009), there has been surprisingly little theoretical work investigating whether results obtained for large-size and infinite networks also apply to small-size networks. We know for example that heterogeneity in the contact structure can markedly lower invasion thresholds in networks of large size (Boguna et al., 2004; Colizza and Vespignani, 2007; Jeger et al., 2007), but there 73 is still only patchy knowledge about the dynamics and properties of small-size networks of various structures. This is of concern, given the several applications of small-size networks 
75 in natural systems and also given that the rapid globalization and structural changes of

76 trade interactions are increasing the relevance of complex networks of small size for the

77 invasion biology of exotic organisms (Jones and Baker, 2007; Dehnen-Schmutz et al., 2007;

78 Brenn et al., 2008). A real world application of directed networks of small size in epidemic

79 controlling are trade movements of infected material amongst plant nurseries (e.g.

80 Bandyopadhyay and Frederiksen, 1999; Anderson et al., 2004; Slippers et al., 2005). A

81 recent example is given by the spread in regional networks of plant nurseries and garden

82 centres of Phytophthora ramorum, the oomycete causing Sudden Oak Death in the West

83 Coast of the USA and leaf blight and dieback in many ornamental shrubs both in America

84 and Europe (Werres et al., 2001; Prospero et al., 2007; Xu et al., 2009). Given the wide range

85 of species affected, movements of infected plant material in the horticultural trade have the

86 potential to make this emerging plant disease outbreak even more widespread

87 (Holdenrieder et al., 2004; Frankel, 2008; Grünwald et al., 2008). There is thus the necessity

88 to control the network of plant nurseries and retail outlets trading ornamental species

89 susceptible to P. ramorum in an effective and efficient way.

90 In this study, we investigated whether heterogeneity in the contact structure and the

91 presence of short-cuts as in small-world networks still make a difference to epidemic

92 development in small-size, directed networks. Directed networks, given the more

93 complicated adjacency matrices, have been used to model epidemics relatively rarely

94 (Newman et al., 2001; Meyers et al., 2006; Park and Kim, 2006; Kenah and Robins, 2007),

95 but are relevant to many real-world situations with asymmetries in contact structures, and

96 deserve more study for various network sizes, structures and levels of connectance. We

97 have shown elsewhere (Pautasso and Jeger, 2008) that heterogeneity in the contact

98 structure still affects the epidemic threshold even in the case of networks of one hundred

99 nodes, but inquire here whether variations in the epidemic threshold (the boundary

100 between no epidemic and an epidemic) for different network structures and at different

101 levels of connectance can be explained by the correlation coefficient between links to and

102 from nodes and by the clustering coefficient of the network. Previous work in percolation

103 theory suggests that the correlation coefficient between links to and from nodes is

104 important in the case of heterogeneity in the contact structure (Schwartz et al., 2002; 
105 Woolhouse et al., 2005; Kao et al., 2006), but it is unclear whether or not this importance is

106 maintained for small-size networks with different (i) size, (ii) structure (local, random,

107 small-world and scale-free), (iii) levels of connectance, and (iv) clustering.

\section{Materials and Methods}

109 We simulated disease spread and establishment in networks of 100 and 500 nodes. For both

110 network sizes, we used six kinds of structure: (1) local (nearest-neighbour transmission), (2)

111 random (nodes connected with probability p), (3) small-world (local networks rewired

112 with short-cuts), and scale-free structure (see Jeger et al., 2007 for a visualization). For

113 scale-free networks, we considered separately networks with in- and out-degree of nodes

114 (4) positively, (5) not and (6) negatively correlated. The networks were directed, i.e. a link

115 from node a to node b did not imply the reverse connection (as e.g. in Newman et al., 2001;

116 Boguna and Serrano, 2005; Meyers et al., 2006; Park and Kim, 2006). Directed networks are

117 realistic approximations of many real world systems; wherever a directed link does not

118 entail the reverse connection (asymmetrical interactions), from food webs to plant-animal

119 mutualistic networks, from infectious disease epidemiology to the spread of information

120 (Bascompte et al., 2003; da Gama and Nunes, 2006; Bode et al., 2008; Thebault and

121 Fontaine, 2008).

122 For each network structure, 100 replicates were built in MATLAB at each level of

123 connectance (for 100 nodes: 100, 200, 400, and 1000 links; for 500 nodes: 500, 2500, 5000, and

12410000 links; Table 1). Rather than keeping connectance constant between the two network

125 sizes, we needed a lower level of connectance for 500 nodes (500 links, i.e. connectance $=$

126 0.002) to obtain results similar to the lower level of connectance for 100 nodes (100 links, i.e.

127 connectance $=0.01$ ) . To obtain a disappearance of a significant correlation between

128 epidemic threshold and correlation links in and out for the larger network size (500 nodes),

129 it was necessary to use a lower connectance level that at network size equal 100 nodes. We

130 also left out results from the highest level of connectance for 500 nodes (25000 links, i.e.

131 connectance $=0.1$ ) as in this case networks were overly connected so that differences

132 between network structures were likely to be small. Local networks were built starting

133 from a regular ring with 100 (for 100 nodes) and 500 (for 500 nodes) links more than the 
134 target number of links and by randomly generating 100 or 500 gaps, respectively. Random

135 digraphs were generated using the $\mathrm{G}(\mathrm{N}, \mathrm{M})$ model where $\mathrm{M}$ directed links are placed

136 randomly and independently between the $\mathrm{N}$ nodes of the graph. Small-world networks

137 were built with the Watts and Strogatz (1998) algorithm and a rewiring coefficient of 0.25.

138 This rewiring coefficient allowed the construction of small-world networks with clustering

139 intermediate between those of random and of local networks. Small-world networks are

140 networks with high clustering compared to random networks and small shortest path

141 length compared to local networks, and these conditions were respected in our case. Scale-

142 free networks were built with a preferential attachment algorithm, starting with a seed

143 network and based on five parameters adding nodes and/or links depending on the in-,

144 out-, and total degree of existing nodes:

1) The parameter a added both a node $i$ and an arrow $(i, j)$ according to the in-degree of an existing node $\mathrm{j}$. This step was repeated a-times.

2) The parameter $b$ added both a node $i$ and an arrow $(j, i)$ according to the out-degree of an existing node $j$. This step was repeated b-times.

3) The parameter c added both a node $i$ and an arrow $(\mathrm{i}, \mathrm{j})$ or $(\mathrm{j}, \mathrm{i})$ according to the total degree of an existing node $\mathrm{j}$. The choice of the direction of each arrow added, i.e. $(\mathrm{i}, \mathrm{j})$ or $(\mathrm{j}, \mathrm{i})$, was equally probable. This step was repeated c-times.

4) The parameter $d$ only added an arrow $(\mathrm{i}, \mathrm{j})$ and not a node according to the outdegree of an existing node $i$ and to the in-degree of an existing node $j(i \neq j)$. This step was repeated d-times.

Epidemic development was deterministic, with discrete time-step and governed by the

5) The parameter e only added an arrow $(i, j)$ and not a node according to the total degrees of existing nodes $i$ and $j(i \neq j)$. This step was repeated e-times. probabilities of infection transmission between nodes $\left(p_{t}\right)$ and of infection persistence in a node $\left(p_{p}\right)$. The transmission probability $p_{t}$ was either zero (unconnected nodes) or a value constant for different links in a network but variable amongst network replicates (in order to work at the threshold conditions in each replicate; see Pautasso and Jeger, 2008). The 
162 persistence probability $p_{p}$ combined in one single parameter the length of infectiousness,

163 detection and control measures. We also set $p_{p}$ to be the same for all nodes. Both $p_{t}$ and $p_{p}$

164 are real variables, going from 0 to 1 . This can be a realistic assumption for many ecological

165

166

167

168

169

170

171

172

173

174

175

176

177

178

179

180

181

182

183

184

185

186

187

188

189

190 networks, wherever persistence and transmission are not either switched on or off, but can assume any value between these two extremes. We assumed all nodes to be of equal capacity and kind (differences between nodes are thus entirely due to their in- and outdegree). At each iteration, the contact structure of the network realization was maintained exactly the same. Networks were not necessarily fully connected, so it is possible that at the lower levels of connectance not all nodes could be reached from all nodes.

For each iteration, we obtained the infection status of a given node $P_{i(x)}$ in the following way:

$P_{i(\mathrm{x})}=\Sigma p_{t(\mathrm{x}, \mathrm{y})} P_{i(\mathrm{y})}$

for $y$ going from 1 to 100 , where $\mathrm{p}_{\mathrm{t}}$ refers to the connection of the node $\mathrm{x}$ from a node $\mathrm{y}$, and $P_{i(y)}$ is the infection status of the node $y$ at the previous iteration. At the beginning of the epidemic $P_{i(\mathrm{x})}$ was set to zero for all nodes except for the starting node of the epidemic, with $P_{(i)}=1$. For the connection of a node with itself, $p_{p}$ was used instead of $p_{t}$. The biological motivation for self-loops is that nodes which have become infected by a pathogen have a certain probability to remain infected due to the persistence of inoculum through time. The model was thus a SIS (Susceptible-Infected-Susceptible) model. This can be a realistic assumption for many epidemiological systems, wherever nodes are still at risk even after eradication of a disease outbreak if complete immunization is not possible and if there is a continuing trade or contact with susceptible material or inoculum (Jeger et al., 2007).

The development of the epidemic was assessed on the basis of the sum of $P_{i(x)}$ across all nodes and on the basis of the number of nodes with $P_{i(x)}$ higher than an arbitrary value (0.01). The epidemic was started with a single infection of a single node, as the threshold conditions were not affected by whether epidemics are started with a single or with multiple infections (unpublished observations). Also, results were consistent using a different starting probability of infection. Although the starting node had a marked 
191 influence on the epidemic size at equilibrium (Pautasso and Jeger, 2008), making the

192

193

194

195

196

197

198

199

200

201

202

203

204

205

206

207

208

209

210

211

212

213

214

215

216

epidemic start from different nodes did not affect the threshold conditions $\left(p^{*} p\right.$ and $p^{*}$ ) which define a boundary between no epidemic and an epidemic. Given that there is a linear threshold in a graph of $p^{*}$ as a function of $p^{*}$ (Pautasso and Jeger, 2008), we worked at $p^{*}=0$ and assessed the threshold only in terms of $p^{*}$.

The clustering coefficient $C_{i}$ of a node $i$ which is part of a digraph characterizes the extent to which nodes adjacent to any node i are adjacent to each other. More precisely,

$$
C_{i}=\frac{\operatorname{Card}\left(E_{\Gamma i}\right)}{\operatorname{Card}\left(V_{\Gamma i}\right) \times\left[\operatorname{Card}\left(V_{\Gamma i}\right)-1\right]}
$$

where Card $(X)$ symbolyses the cardinality of the set $X$, i.e. the number of elements of $X$. The neighbourhood $\Gamma_{i}$ of a vertex $i$ is the digraph that consists solely of the set $V_{\Gamma i}$ of vertices connected from and/or to $i$ (not including $i$ itself) and of the set $E_{\Gamma i}$ of all arrows connecting such vertices. The average clustering $C$ of a digraph is the average of the clustering of each node of this digraph.

Analysis of variance (ANOVA) of the epidemic threshold and of the correlation coefficient between in- and out-degree of the 100 nodes of the network replicates for the different levels of connectance (within a network structure) and for the different types of network structure (at a given level of connectance) was carried out in SAS 9.1 (proc ANOVA). The same package (proc GLM) was used for multi-variate regressions of the threshold $p^{*}{ }_{t}$ against the correlation coefficient between in- and out-degree and the average clustering coefficient of the $100 / 500$ nodes of the network replicate for a given network structure and level of connectance.

\section{Results}

The threshold $p_{t}^{*}$ significantly decreased with increasing connectance for all structures and with both network sizes (Fig. 1a, b). With the exception of the lowest connectance level for both network sizes, two-way scale-free networks showed a significantly lower and oneway scale-free networks a significantly higher threshold than all other structures (Fig. 1c, 
217 d). For network size of 100 nodes, random networks showed a significantly lower

218 threshold than local networks, but not at the highest connectance (Fig 1c). This result was

219 not confirmed at the larger network size, where random networks had an epidemic

220 threshold not significantly different than the one of local networks (Fig. 1d). Small-world

221 networks showed a threshold not significantly different from random networks (except at

222 the lowest connectance for both network sizes). The threshold of uncorrelated scale-free

223 networks, at all connectance levels and for both network sizes, lay between those for two-

224 way and one-way scale-free networks (Fig. 1c, d).

225 The correlation coefficient between in- and out-degree of the nodes of the networks was, by

226 definition, positive for two-way scale-free networks, not significantly different from zero

227 for uncorrelated scale-free networks (except, by chance, at some levels of connectance; Fig.

228 1e, f), and negative for one-way scale-free networks. This coefficient was also clustered

229 around zero for local, small-world and random networks. There was a significant increase

230 in the correlation coefficient between in- and out-degree for two-way scale-free networks

231 with increasing connectance for both network sizes (Fig. 1g, h).

232 With the exception of the lowest connectance, there were generally significantly negative

233 relationships between threshold $p^{*}$ and the correlation coefficient between in- and out-

234 degree for all structures and with both network sizes (Fig. 2; Tables 2, 3). At the lowest

235 level of connectance, these relationships were significant only for small-world and two-

236 way scale-free networks for the network size of 100 nodes. The proportion of variance in

237 threshold $p^{*}$ explained by the correlation between the in- and the out-degree increased

238 with connectance for all structures and for both network sizes, but with exception of two-

239 way scale-free networks. Apart from one-way scale-free networks for 500 nodes and two-

240 way scale-free networks for both network sizes, at the highest connectance these

241 proportions of variance were substantial (between 0.84 and 0.93 for 100 nodes, and

242 between 0.56 and 0.95 for 500 nodes). However, apart from one-way scale-free networks at

243 the network size of 100 nodes, the slopes of these relationships tended to become flatter

244 with increasing connectance (Tables 2,3). This is a consequence of the overall lower

245 threshold $p^{*}$ at higher connectance (Fig. 2). 
246 Including the clustering as an additional explaining factor in the regression of the

247 threshold $p^{*}$ against the correlation coefficient between links to and from nodes did not

248 affect the previous results. The clustering increased with increasing level of connectance for

249 all structures and for both network sizes (Figs. 3, 4). By definition, at a given connectance,

250 the clustering was higher in local than in small-world networks, and in small-world

251 compared to random networks (Figs. 3, 4). The clustering also decreased from two-way to

252 uncorrelated and to one-way scale-free networks (Figs. 3, 4). For both network sizes, the

253 clustering was significantly negatively related to the threshold $\mathrm{p}_{\mathrm{t}}$ at the lowest level of

254 connectance for local and small-world networks, and at all levels of connectance for two

255 way scale-free networks (Fig. 3; Tables 2, 3).

256 For both network sizes, the relationship of the correlation coefficient between links to and

257 from nodes with the clustering was significantly positive for all scale-free networks (except

258 at the lowest level of connectance; Fig. 4; Tables 4, 5). However, the proportion of variance

259 in the correlation coefficient between in- and out-degree explained by the clustering was

260 substantial for uncorrelated and one-way, but not for two-way scale-free networks. For

261 both network sizes, there was also a significantly positive correlation between these two

262 variables for random networks at the two highest connectance levels (Tables 4, 5).

\section{Discussion}

264 Networks of small size have biological significance in a variety of ecological fields.

265 Examples include meta-populations, mutualistic and antagonistic interactions (Dunne et

266 al., 2002; Lundgren and Olesen, 2005; Brooks, 2006; Pautasso et al., 2008; Thebault and

267 Fontaine, 2008). In spite of the relevance of small-size networks for many issues in natural

268 sciences, it is not clear whether theoretical results derived from analyses of large-scale

269 complex networks apply also to small-size networks (Guimarães et al., 2007). Moreover,

270 much work in network epidemiology has focused on undirected networks (e.g. Keeling,

271 2005; Shirley and Rushton, 2005; May, 2006), whereas many of the biological networks

272 mentioned in the Introduction are inherently asymmetrical and thus can only be

273 realistically modelled with directed networks. 
274 Our analysis shows that in SIS models of epidemics in directed networks of small size, the

275 threshold is lower for scale-free network structures only if there is a positive correlation

276 between in- and out-degree of nodes (Fig. 2). This finding is in good agreement with results

277 obtained in percolation theory for large-size networks (Schwartz et al., 2002). Our work

278 further shows that when this correlation between in- and out-degree of nodes is negative

279 (one-way scale-free networks), for small-size networks the epidemic threshold is higher

280 than in non scale-free networks. This result is broadly independent of the connectance level

281 and of the network size, although it breaks down in case of sparsely connected networks.

282 For sparsely connected networks, differences in clustering amongst networks can become 283 important.

284 Clustering has been shown to be a network feature relevant to the development and 285 control of epidemics (e.g. Eames and Keeling, 2003; Keeling, 2005; Kiss et al., 2005;

286 Hartivgsen et al., 2007; Turner et al., 2008; Miller, 2009). More clustered networks are

287 believed to be less prone to invasion by a pathogen, as this will be likely to become 288 confined inside clusters of connected nodes (Keeling, 2005; Naug, 2008). Clusters can also 289 slow down epidemic development in the first phases of epidemics (e.g. Szendroi and 290 Csanyi, 2004). In scale-free networks of infinite size, the presence of high local clustering 291 has been shown to make it possible for a non-null epidemic threshold to be present 292 (Eguiluz and Klemm, 2002; but see Serrano and Boguna, 2006). Clustering in large-scale 293 scale-free networks has been shown to decrease the size of epidemics, but also to decrease 294 their threshold (Newman, 2003).

295 In the case of our small-size networks, the influence of clustering on the epidemic 296 threshold is dwarfed by the one of the correlation coefficient between in- and out-degree.

297 The negative correlation between epidemic threshold and clustering for uncorrelated and 298 one-way scale-free networks at the highest levels of connectance (Fig. 3) can be explained 299 by the positive correlation of the correlation coefficient between in- and out-degree with 300 the clustering in the same networks (Fig. 4). Unlike Eames (2008) for undirected networks, 301 we do not observe any differences in the influence of clustering on epidemic development 302 depending on whether contacts are regular or random. In our small-size, directed 
303

304

305

306

307

308

309

310

311

312

313

314

315

316

317

318

319

320

321

322

323

324

325

326

327

328

329

330

331

networks, with the exception of sparsely connected local networks, clustering has no influence on the epidemic threshold within both local and random networks (Fig. 3).

Our main conclusion is that, in directed networks, analyses of the influence of clustering on the epidemic threshold can be spurious if they do not consider simultaneously the effect of the correlation coefficient between in-and out-degree. In some cases (sparsely connected local, small-world and two-way scale free networks), we observe a negative correlation between epidemic threshold and clustering and no significant effect of the correlation coefficient between in- and out- degree on the threshold, suggesting that in extreme situations the correlation coefficient between in- and out-degree may not play the same role as for large-scale networks. We also point out that analyses which show that clustering is negatively related to the epidemic threshold (e.g. Britton et al., 2008) need to take the connectance level into account, as (i) the clustering increases with increasing connectance, (ii) the epidemic threshold decreases with increasing connectance, so that (iii) if connectance increases the epidemic threshold is bound to be negatively correlated with the clustering. Our results show, however, that, when keeping connectance constant, clustering and epidemic threshold are not necessarily related.

Epidemics in scale-free networks are now commonly investigated (e.g. Boccaletti et al., 2006; Masuda and Konno, 2006; Colizza and Vespignani, 2008), but there has been less attention to directed scale-free networks. In this analysis, we confirm the importance of the correlation coefficient between in-and out-degree for epidemics in directed scale-free networks (Woolhouse et al., 2005). We also provide evidence for a different behaviour of the clustering in directed scale-free networks where there are different correlation coefficients between in- and out-degree. Although there is a positive correlation of the clustering with the correlation coefficient between in-and out-degree for all scale-free network types (except at the lowest connectance level), only for uncorrelated and one-way scale-free networks has this correlation a substantial $\mathrm{r}^{2}$ (for 500 nodes: between 0.54 and 0.79 , Table 5). For two-way scale-free networks, the correlation between clustering and correlation coefficient between links in and out of nodes is significant but negligible (again for 500 nodes, $\mathrm{r}^{2}$ values are between 0.01 and 0.08 , Table 5). Further work is needed to 
332 investigate whether results obtained for undirected scale-free networks apply to all types 333 of directed scale-free networks.

334 Our results are essentially independent of the network size used (100 and 500 nodes). We

335

336

337 have avoided using a lower number of nodes than 100 as it is likely that differences between network structures will tend to become blurred for even smaller networks. However, an interesting question would be at which small size heterogeneity in the contact structure stops having a significant influence on network properties and epidemic processes. A remarkable result is also that network breakdown at the lowest connectance level (which causes for example the disappearance of a significant relationship between epidemic threshold and correlation coefficient between in- and out-degree) happens at two different connectance levels ( 0.01 for 100 nodes and 0.002 for 500 nodes, Table 1 ) for the two network sizes. More research is needed to assess which other processes are not independent of the interaction between network size and connectance.

In conclusion, our study confirms the result obtained for large-size networks that regardless of the size of the network, the epidemic threshold is negatively related to the correlation coefficient between in- and out-degree for all structures. However, this does not hold if small-size networks are sparsely connected. In this case, clustering plays a significant role (Table 2). In small-size networks, when the correlation between links in and out is negative (one-way scale-free networks), the epidemic threshold can be higher than in non scale-free networks. Contrary to what is found in analyses of large-size networks, clustering does not necessarily have an influence on the epidemic threshold of small-size networks if connectance is kept constant. Analyses of the influence of the clustering on the epidemic threshold in directed networks can also be spurious if the effect of the correlation coefficient between in- and out-degree is disregarded.

\section{Acknowledgments}

Many thanks to T. Harwood, O. Holdenrieder, J. Parke, M. Shaw, J. Tufto, F. Van den Bosch and X. Xu for discussions and insights, and to T. Matoni and anonymous reviewers for helpful comments on a previous version of the ms. This study was funded by the Department for Environment, Food and Rural Affairs, the Rural Economy and Land Use Programme, UK, and the French Ministry of National Education and Research. 


\section{References}

362 Anderson, P.K., Cunningham, A.A., Patel, N.G., Morales, F.J., Epstein, P.R., Daszak, P., 2004. Emerging

363 infectious diseases of plants: pathogen pollution, climate change and agrotechnology drivers. Trends Ecol.

364 Evol. 19, 535-544.

365 Bandyopadhyay, B., Frederiksen, R.A., 1999. Contemporary global movement of emerging plant diseases.

366 Ann. New York Acad. Sci. 894, 28-36.

367 Bascompte, J., 2007. Networks in ecology. Basic Appl. Ecol. 8, 485-490.

368 Bascompte, J., Jordano, P., Melian, C.J., Olesen, J.M., 2003. The nested assembly of plant-animal mutualistic 369 networks. Proc. Natl. Acad. Sci. USA 100, 9383-9387.

370 Blanc, L.A., Walters, J.R., 2007. Cavity-nesting community webs as predictive tools: where do we go from

371 here? J. Ornithology 148, S417-S423.

372 Boccaletti, S., Latora, V., Moreno, Y., Chavez, M., Hwang, D.U., 2006. Complex networks: structure and 373 dynamics. Phys. Rep. 424 (4-5), 175-308.

374 Bode, M., Burrange, K., Possingham, H.P., 2008. Using complex network metrics to predict the persistence of 375 metapopulations with asymmetric connectivity patterns. Ecol. Model. 214, 201-209.

376 Boguna, M., Serrano, M.A., 2005. Generalized percolation in random directed networks. Phys. Rev. E 72, 377016106.

378 Boguna, M., Pastor-Satorras, R., Vespignani, A., 2004. Cut-offs and finite size effects in scale-free networks. 379 Eur. Phys. J. B 38, 205-209.

380 Brenn, N., Menkis, A., Grünig, C.R., Sieber, T.N., Holdenrieder, O., 2008. Community structure of

381 Phialocephala fortinii s. lat. in European tree nurseries, and assessment of the potential of the seedlings as 382 dissemination vehicles. Mycol. Res. 112, 650-662.

383 Britton, T., Deijfen, M., Lageras, A.N., Lindholm, M., 2008. Epidemics on random graphs with tunable 384 clustering. J. Appl. Prob. 45, 743-756.

385 Brooks, C.P., 2006. Quantifying population substructure: extending the graph-theoretic approach. Ecology 87, $386 \quad 864-872$.

387 Brooks, C.P., Antonovics, J., Keitt, T.H., 2008. Spatial and temporal heterogeneity explain disease dynamics in 388 a spatially explicit network model. Am. Nat. 172, 149-159.

389 Burns, K.C., 2007. Network properties of an epiphyte metacommunity. J. Ecol. 95, 1142-1151.

390 Colizza, V., Vespignani, A., 2007. Invasion threshold in heterogeneous metapopulation networks. Phys. Rev. 391 Lett. 99, 148701. 
392

393

394

395

396

397

398

399

400

401

402

403

404

405

406

407

408

409

410

411

412

413

414

415

416

417

418

419

420

421

422

Colizza, V., Vespignani, A., 2008. Epidemic modeling in metapopulation systems with heterogeneous coupling pattern: theory and simulations. J. Theor. Biol. 251 (3), 450-467.

da Gama, M.M.T., Nunes, A., 2006. Epidemics in small world networks. Eur. Phys. J. B 50, 205-208.

Dehnen-Schmutz, K., Touza, J., Perrings, C., Williamson, M., 2007. A century of the ornamental plant trade and its impact on invasion success. Divers. Dist. 13, 527-534.

Dunne, J.A., Williams, R.J., Martinez, N.D., 2002. Food-web structure and network theory: the role of connectance and size. Proc. Natl. Acad. Sci. USA 99, 12917-12922.

Eames, K.T.D., 2008. Modelling disease spread through random and regular contacts in clustered populations. Theor. Pop. Biol. 73, 104-111.

Eames, K.T.D., Keeling, M.J., 2003. Contact tracing and disease control. Proc. R. Soc. London B 270, 2565-2571.

Eguiluz, V.M., Klemm, K., 2002. Epidemic threshold in structured scale-free networks. Phys. Rev. E 89, 108701.

Frankel, S.J., 2008. Sudden oak death and Phytophthora ramorum in the USA: a management challenge. Aust. Plant Path. 24: 282-284.

Grünwald, N.J., Goss, E.M., Press, C.M., 2008. Phytophthora ramorum: a pathogen with a remarkably wide host range causing sudden oak death on oaks and ramorum blight on woody ornamentals. Mol. Plant Path. 9, 729740.

Guimarães, P.R., de Menezes, M.A., Baird, R.W., Lusseau, D., Guimaraes, P., dos Reis, S.F., 2007.

Vulnerability of a killer whale social network to disease outbreaks. Phys. Rev. E 76, 042901.

Hanski, I., Ovaskainen, O., 2000. The metapopulation capacity of a fragmented landscape. Nature 404, 755758.

Hartivgsen, G., Dresch, J.M., Zielinski, A.L., Macula, A.J., Leary, C.C., 2007. Network structure, and vaccination strategy and effort interact to affect the dynamics of influenza epidemics. J. Theor. Biol. 246, 205213.

Holdenrieder, O., Pautasso, M., Weisberg, P.J., Lonsdale D., 2004. Tree diseases and landscape processes: the challenge of landscape pathology. Trends Ecol. Evol. 19, 446-452.

Ings, T.C., Montoya, J.M., Bascompte, J., Bluethgen, N., Brown, L., Dormann, C.F., Edwards, F., Figueroa, D., Jacob, U., Jones, J.I., Lauridsen, R.B., Ledger, M.E., Lewis, H.M., Olesen, J.M., van Veen, F.F.J., Warren, P.H., Woodward, G., 2009. Ecological networks - beyond food webs. J. Anim. Ecol. 78, 253-269.

Jeger, M.J., Pautasso, M., Holdenrieder, O., Shaw, M.W., 2007. Modelling disease spread and control in networks: implications for plant sciences. New Phytol. 174, 279-297.

$6 / 19 / 2009$ 
423

424

425

426

427

428

429

430

431

432

433

434

435

436

437

438

439

440

441

442

443

444

445

446

447

448

449

450

451

452

453

Jones, D.R., Baker, R.H.A., 2007. Introductions of non-native plant pathogens into Great Britain, 1970-2004.

Plant Pathol. 56, 891-910.

Kao, R.R., Danon, L., Green, D.M., Kiss, I.Z., 2006. Demographic structure and pathogen dynamics of the network of livestock movements in Great Britain. Proc. R. Soc. London B 273, 1999-2007.

Keeling, M.J., 2005. The implications of network structure for epidemic dynamics. Theor. Pop. Biol. 67, 1-8.

Kenah, E., Robins, J.M., 2007. Network-based analysis of stochastic SIR epidemic models with random and proportionate mixing. J. Theor. Biol. 249, 706-722.

Kiss, I.Z., Green, D.M., Kao, R.R., 2005. Disease contact tracing in random and clustered networks. Proc. R. Soc. London B 272, 1407-1414.

Lamour, A., Termorshuizen, A.J., Volker, D., Jeger, M.J., 2007. Network formation by rhizomorphs of Armillaria lutea in natural soil: their description and ecological significance. FEMS Microb. Ecol. 62, 222-232.

Liu, J.Z., Wu, J.S., Yang, Z.R., 2004. The spread of infectious disease on complex networks with householdstructure. Physica A 341, 273-280.

Lobel, S., Snall, T., Rydin, H., 2006. Metapopulation processes in epiphytes inferred from patterns of regional distribution and local abundance in fragmented forest landscapes. J. Ecol. 94, 856-868.

Lundgren, R., Olesen, J.M., 2005. The dense and highly connected world of Greenland's plants and their pollinators. Arct. Antarct. Alp. Res. 37, 514-520.

Masuda, N., Konno, N., 2006. Multi-state epidemic processes on complex networks. J. Theor. Biol. 243, 64-75.

May, R.M., 2006. Network structure and the biology of populations. Trends Ecol. Evol. 21, 394-399.

Meyers, L.A., Newman, M.E.J., Pourbohloul, B., 2006. Predicting epidemics on directed contact networks. J. Theor. Biol. 240, 400-418.

Miller, J.C., 2009. Spread of infectious disease through clustered populations. J. Roy. Soc. Interface, in press. doi:10.1098/rsif.2008.0524

Montoya, J.M., Solé, R.V., 2002. Small world patterns in food webs. J. Theor. Biol. 214, 405-412.

Moore C, Newman MEJ (2000) Epidemics and percolation in small-world networks. Phys. Rev. E 61, 56785682.

Naug, D., 2008. Structure of the social network and its influence on transmission dynamics in a honeybee colony. Behav. Ecol. Sociobiol. 62, 1719-1725.

Neutel, A.M., Heesterbeek, J.A.P., van de Koppel, J., Hoenderboom, G., Vos, A., Kaldeway, C., Berendse, F., de Ruiter, P.C., 2007. Reconciling complexity with stability in naturally assembling food webs. Nature 449, 599-602.

$6 / 19 / 2009$ 
454

455

456

457

458

459

460

461

462

463

464

465

466

467

468

469

470

471

472

473

474

475

476

477

478

479

480

481

482 483

Newman, M.E.J., 2003. Properties of highly clustered networks. Phys. Rev. E 68, 026121.

Newman, M.E.J., Strogatz, S.H., Watts, D.J., 2001. Random graphs with arbitrary degree distributions and their applications. Phys. Rev. E 64, 026118.

Nielsen, A., Bascompte, J., 2007. Ecological networks, nestedness and sampling effort. J. Ecol. 95, 1134-1141.

Olesen, J.M., Bascompte, J., Dupont, Y.L., Jordano, P., 2006. The smallest of all worlds: pollination networks. J. Theor. Biol. 240, 270-276.

Otterstatter, M.C., Thomson, J.D., 2007. Contact networks and transmission of an intestinal pathogen in bumble bee (Bombus impatiens) colonies. Oecologia 154, 411-421.

Park, S.M., Kim, B.J., 2006. Dynamic behaviors in directed networks. Phys. Rev. E 74, 026114.

Pastor-Satorras, R., Vespignani, A., 2001. Epidemic spreading in scale-free networks. Phys. Rev. Lett. 86, 32003203.

Pautasso, M., Jeger, M.J., 2008. Epidemic threshold and network structure: the interplay of probability of transmission and of persistence in small-size directed networks. Ecol. Compl. 5, 1-8.

Pautasso, M., Harwood, T., Shaw, M.W., Xu, X., Jeger, M.J., 2008. Epidemiological modeling of Phytophthora ramorum: network properties of susceptible plant genera movements in the nursery sector of England and Wales. Proc Sudden Oak Death III Science Symposium, PSW-GTR-214, USDA Forest Service, pp. 257-264.

Pellis, L., Ferguson, N.M., Fraser, C., 2009. Threshold parameters for a model of epidemic spread among households and workplaces. J. R. Soc. Interface, in press doi:10.1098/rsif.2008.0493

Prospero, S., Hansen, E.M., Grunwald, N.J., Winton, L.M., 2007. Population dynamics of the sudden oak death pathogen Phytophthora ramorum in Oregon from 2001 to 2004. Mol. Ecol. 16, 2958-2973.

Proulx, S.R., Promislow, D.E.L., Phillips, P.C., 2005. Network thinking in ecology and evolution. Trends Ecol. Evol. 20, 345-353.

Ryder, T.B., McDonald, D.B., Blake, J.G., Parker, P.G., Loiselle, B.A., 2008. Social networks in the lek-mating wire-tailed manakin (Pipra filicauda). Proc. R. Soc. London B 275, 1367-1374.

Schwartz, N., Cohen, R., ben-Avraham, D., Barabasi, A.L., Havlin, S., 2002. Percolation in directed scale-free networks. Phys. Rev. E 66, 015104.

Serrano, M.A., Boguna, M., 2006. Percolation and epidemic thresholds in clustered networks. Phys. Rev. Lett. $97,088701$.

Shirley, M.D.F., Rushton, S.P., 2005. The impact of network topology on disease spread. Ecol. Compl. 2, 287299.

$6 / 19 / 2009$ 
Slippers, B., Stenlid, J., Wingfield, M.J., 2005. Emerging pathogens: fungal host jumps following anthropogenic introduction. Trends Ecol. Evol. 20, 420-421

Southworth, D., He, X.H., Swenson, W., Bledsoe, C.S., Horwath, W.R., 2005. Application of network theory to potential mycorrhizal networks. Mycorrhiza 15, 589-595.

Sun, H.J., Gao, Z.Y., 2007. Dynamical behaviors of epidemics on scale-free networks with community structure. Physica A 381, 491-496.

Szendroi, B., Csanyi, G., 2004. Polynomial epidemics and clustering in contact networks. Proc. R. Soc. London B 271, S364-S366.

Thebault, E., Fontaine, C., 2008. Does asymmetric specialization differ between mutualistic and trophic networks? Oikos 117, 555-563.

494 Turner, J., Bowers, R.G., Clancy, D., Behnke, M.C., Christley, R.M., 2008. A network model of E. coli O157 495 transmission within a typical UK dairy herd: the effect of heterogeneity and clustering on the prevalence of 496 infection. J. Theor. Biol. 254, 45-54.

497 Watts, D.J., Strogatz, S.H., 1998. Collective dynamics of 'small-world' networks. Nature 393, 440-442.

498 Werres, S., Marwitz, R., Veld, W.A.M.I., De Cock, A.W.A.M., Bonants, P.J.M., De Weerdt, M., Themann, K., 499 Ilieva, E., Baayen, R.P., 2001. Phytophthora ramorum sp nov., a new pathogen on Rhododendron and Viburnum. 500 Mycol. Res. 105: 1155-1165.

501 Woolhouse, M.E.J., Shaw, D.J., Matthews, L., Liu, W.C., Mellor, D.J., Thomas, M.R., 2005. Epidemiological 502 implications of the contact network structure for cattle farms and the 20-80 rule. Biol. Lett. 1, 350-352.

503 Xu, X.M., Harwood, T.D., Pautasso, M., Jeger, M.J., 2009. Spatio-temporal analysis of Phytophthora ramorum 504 cases in England and Wales (2003-2006). Ecography, in press 
505 Table 1. Number of links $(\mathrm{L})$ and connectance $\left(\mathrm{C}=\mathrm{L} / \mathrm{N}^{2}\right)$ for the two network sizes studied 506 (number of nodes $=\mathrm{N}$ ).

\begin{tabular}{lrrrr}
\hline $\mathrm{N}$ & 100 & & & \\
$\mathrm{~L}$ & 100 & 200 & 400 & 1000 \\
$\mathrm{C}$ & 0.01 & 0.02 & 0.04 & 0.1 \\
\hline $\mathrm{N}$ & 500 & & & \\
$\mathrm{~L}$ & 500 & 2500 & 5000 & 10000 \\
$\mathrm{C}$ & 0.002 & 0.01 & 0.02 & 0.04 \\
\hline
\end{tabular}

507

508 
508 Table 2. Proportion of variance explained, slope and associated $\mathrm{p}$ value of the regression of 509 threshold probability of transmission as a function of (a) the correlation coefficient between 510 in- and out-degree and (b) the clustering for the 100 replicates of the six network structures 511 (local, random, small-world, two-way, uncorrelated, and one-way scale-free) at four levels

512 of connectance $(100,200,400$ and 1000 links; network size $=100$ nodes).

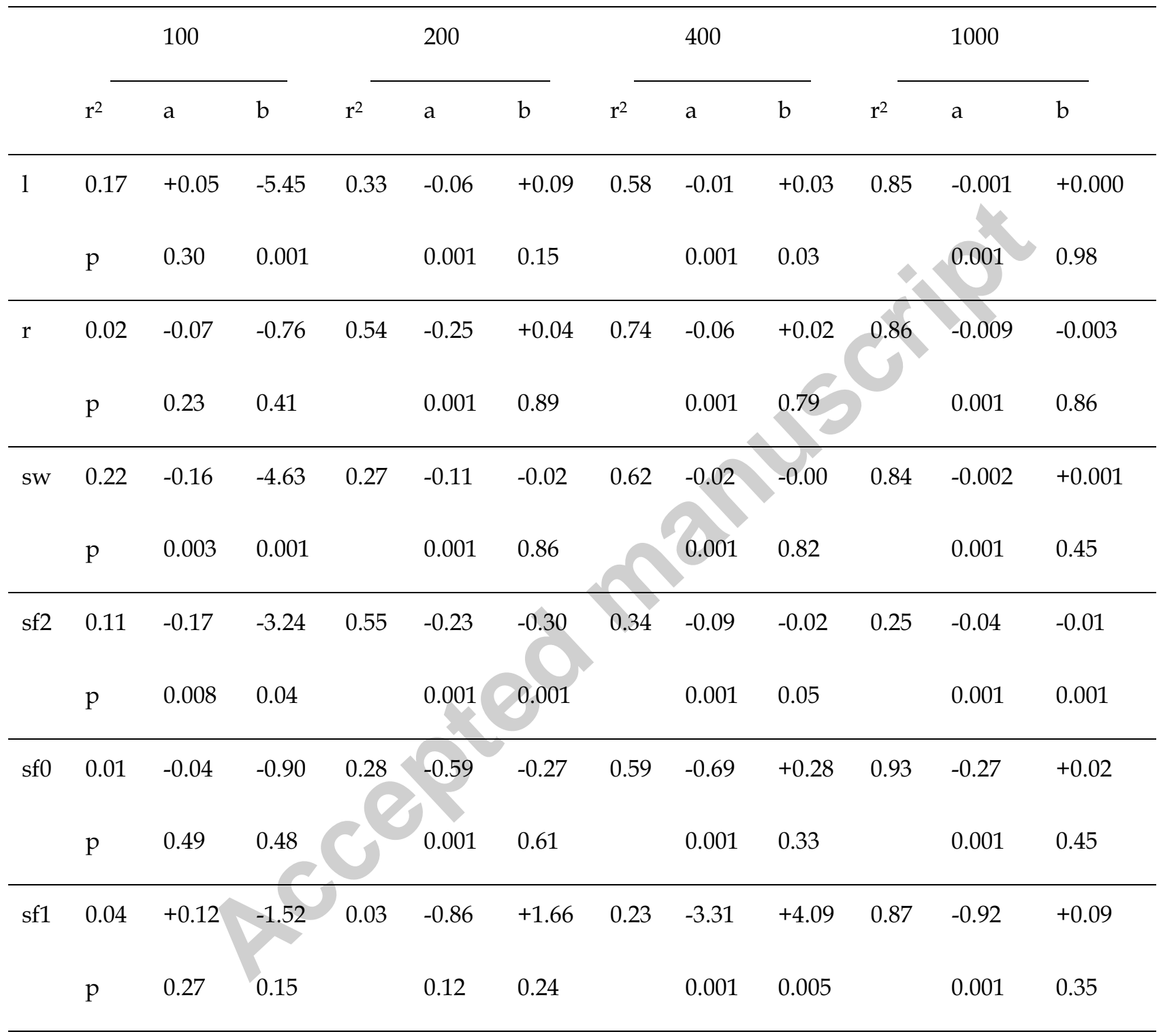

513

514 
514 Table 3. Proportion of variance explained, slope and associated $p$ value of the regression of

515 threshold probability of transmission as a function of (a) the correlation coefficient between

516 in- and out-degree and (b) the clustering for the 100 replicates of the six network structures 517 (local, random, small-world, two-way, uncorrelated, and one-way scale-free) at four levels 518 of connectance $(500,2500,5000$ and 10,000 links; network size $=500$ nodes).

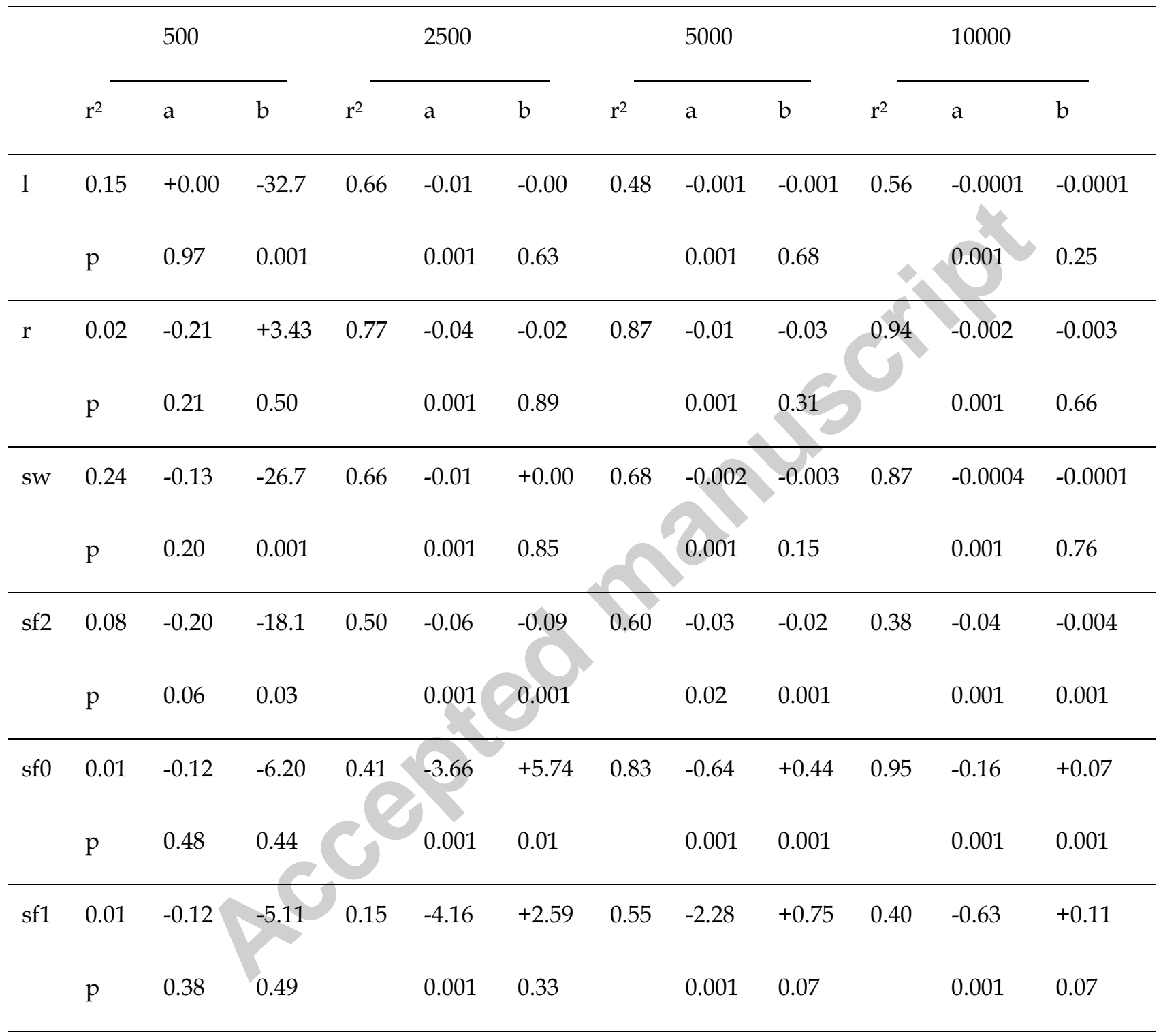

519

520

521 
521 Table 4. Proportion of variance explained, slope and associated $p$ value of the regression of 522 the correlation coefficient between in- and out-degree as a function of the clustering for the 523100 replicates of the six network structures (local, random, small-world, two-way,

524 uncorrelated, and one-way scale-free) at four levels of connectance (100, 200, 400 and 1000 525 links; network size $=100$ nodes).

\begin{tabular}{|c|c|c|c|c|c|c|c|c|c|c|c|c|}
\hline & & 100 & & & 200 & & & 400 & & & 1000 & \\
\hline & $r^{2}$ & slope & $\mathrm{p}$ & $\mathrm{r}^{2}$ & slope & $\mathrm{p}$ & $\mathrm{r}^{2}$ & slope & $\mathrm{p}$ & $\mathrm{r}^{2}$ & slope & $\mathrm{p}$ \\
\hline 1 & 0.06 & -7.40 & 0.01 & 0.00 & -0.01 & 0.99 & 0.00 & +0.26 & 0.85 & 0.00 & -0.93 & 0.88 \\
\hline $\mathrm{r}$ & 0.00 & -0.65 & 0.69 & 0.01 & +0.14 & 0.37 & 0.07 & +5.37 & 0.008 & 0.06 & +10.1 & 0.01 \\
\hline sw & 0.00 & -0.84 & 0.68 & 0.01 & -0.49 & 0.41 & 0.03 & +1.55 & 0.09 & & +0.33 & 0.83 \\
\hline $\mathrm{sf} 2$ & 0.00 & +1.46 & 0.56 & 0.18 & +1.13 & 0.001 & 0.04 & +0.16 & 0.04 & 0.06 & +0.05 & 0.01 \\
\hline sf0 & 0.00 & -0.03 & 0.98 & 0.13 & +1.81 & 0.001 & 0.65 & & 0.001 & 0.70 & +1.83 & 0.001 \\
\hline sf1 & 0.05 & -2.02 & 0.03 & 0.08 & +0.71 & 0.005 & 0.42 & +1.50 & 0.001 & 0.69 & +1.37 & 0.001 \\
\hline
\end{tabular}


527 Table 5. Proportion of variance explained, slope and associated $\mathrm{p}$ value of the regression of 528 the correlation coefficient between in- and out-degree as a function of the clustering for the 529100 replicates of the six network structures (local, random, small-world, two-way, 530 uncorrelated, and one-way scale-free) at four levels of connectance (500, 2500, 5000 and 53110000 links; network size $=500$ nodes $)$.

\begin{tabular}{|c|c|c|c|c|c|c|c|c|c|c|c|c|}
\hline & \multicolumn{3}{|c|}{500} & \multicolumn{3}{|c|}{2500} & \multicolumn{3}{|c|}{5000} & \multicolumn{3}{|c|}{10000} \\
\hline & $\mathrm{r}^{2}$ & slope & $\mathrm{p}$ & $\mathrm{r}^{2}$ & slope & $\mathrm{p}$ & $\mathrm{r}^{2}$ & slope & $\mathrm{p}$ & $\mathrm{r}^{2}$ & slope & $\mathrm{p}$ \\
\hline 1 & 0.05 & -45.5 & 0.03 & 0.00 & +1.61 & 0.48 & 0.00 & -3.40 & 0.46 & 0.00 & -4.90 & 0.52 \\
\hline$r$ & 0.01 & +3.08 & 0.32 & 0.02 & +7.42 & 0.21 & 0.09 & +22.4 & 0.002 & 0.06 & +25.0 & 0.01 \\
\hline sw & 0.00 & +2.67 & 0.59 & 0.00 & +0.05 & 0.96 & 0.00 & +0.02 & 0.98 & 0,00 & -0.84 & 0.60 \\
\hline sf2 & 0.00 & -0.37 & 0.96 & 0.08 & +0.19 & 0.005 & 0.09 & +0.04 & 0.002 & 0.01 & +0.01 & 0.33 \\
\hline sf0 & 0.00 & +2.82 & 0.55 & 0.73 & +3.33 & 0.001 & 0.79 & +218 & 0.001 & 0.71 & +1.71 & 0.001 \\
\hline sf1 & 0.00 & -1.63 & 0.75 & 0.54 & +1.60 & 0.001 & 0.74 & +1.10 & 0.001 & 0.55 & +0.45 & 0.001 \\
\hline
\end{tabular}


533 Figure legends

534 Fig. 1: Threshold probability of transmission for the different $(a, b)$ levels of connectance

535 and (c, d) network structures, and correlation coefficient between in- and out-degree of the 536 nodes of the 100 replicates for the different $(e, f)$ levels of connectance and $(g, h)$ network structures. Network size $=100(\mathrm{a}, \mathrm{c}, \mathrm{e}, \mathrm{g})$ and 500 (b, d, e, h) nodes. Error bars are standard 538 deviations of 100 replicates. Different letters show significant differences (ANOVA, $\mathrm{p}<$ $0.05)$ within $(a, b, e, f)$ levels of connectance for a given network structure, and (c, d, g, h) network structures for a given level of connectance.

541 Fig. 2: Threshold probability of transmission for the different network replicates as a 542 function of the correlation coefficient between in- and out-degree of the nodes for the six 543 network structures. Network size $=100$ nodes (number of links $=$ (a) 100, (b) 200, (c) 400, 544 and (d) 1000) and 500 nodes (number of links = (e) 500, (f) 2500, (g) 5000, and (h) 10000).

545 Fig. 3: Threshold probability of transmission for the different network replicates as a 546 function of the average clustering coefficient of the nodes for the six network structures.

547 Network size $=100$ nodes (number of links = (a) 100, (b) 200, (c) 400, and (d) 1000) and 500 548 nodes (number of links = (e) 500, (f) 2500, (g) 5000, and (h) 10000).

549 Fig. 4: Correlation coefficient between in- and out-degree for the different network 550 replicates as a function of the average clustering coefficient of the 100 nodes for the six 551 network structures. Network size $=100$ nodes (number of links $=(a)$ 100, (b) 200, (c) 400, 552 and (d) 1000) and 500 nodes (number of links = (e) 500, (f) 2500, (g) 5000, and (h) 10000). 


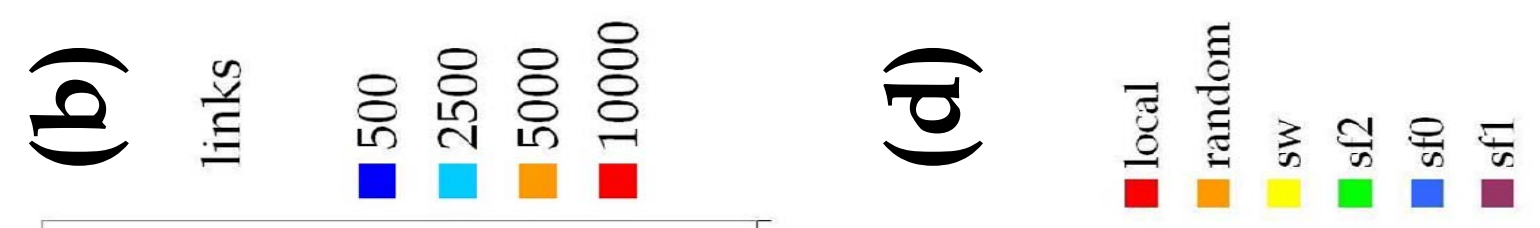

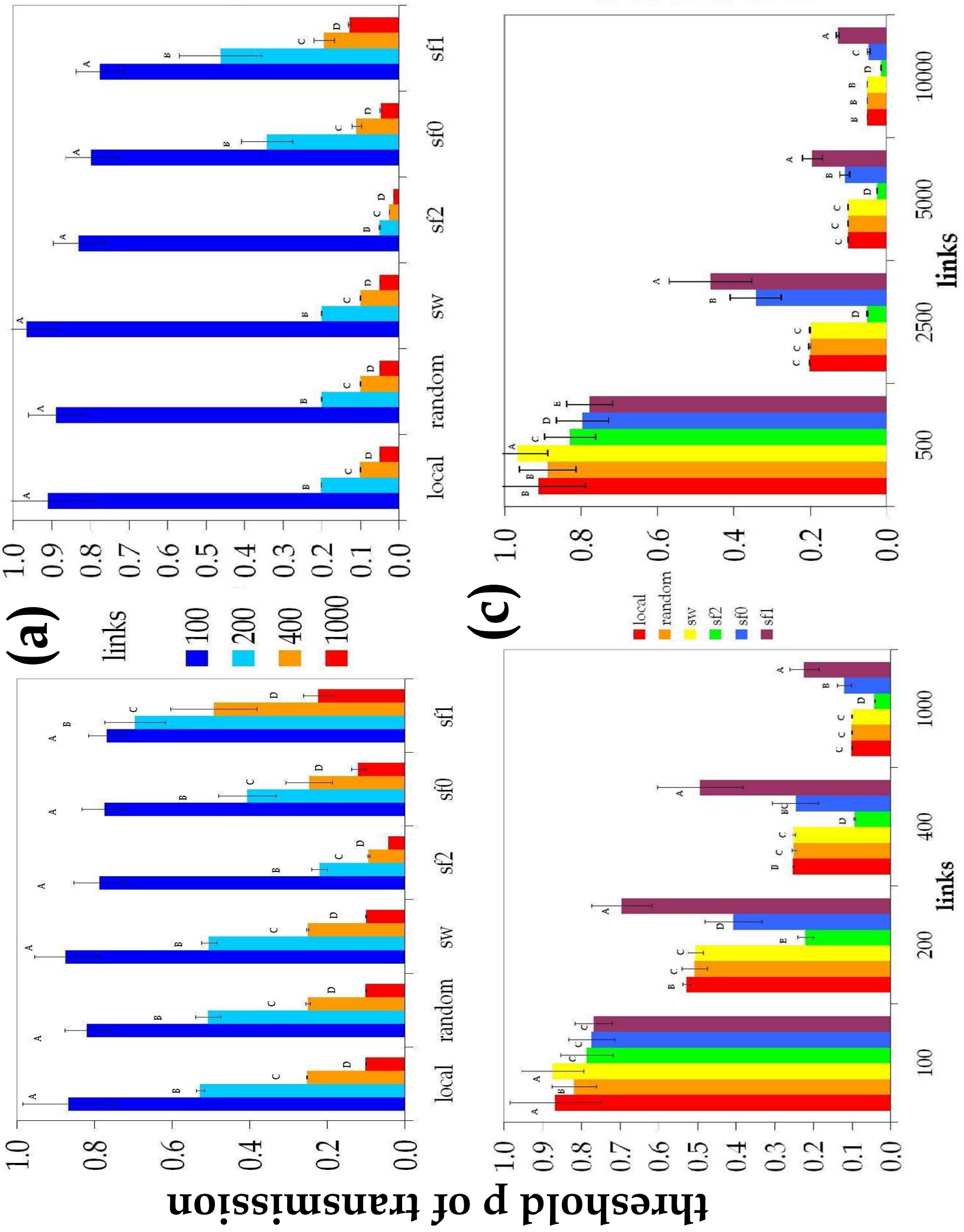




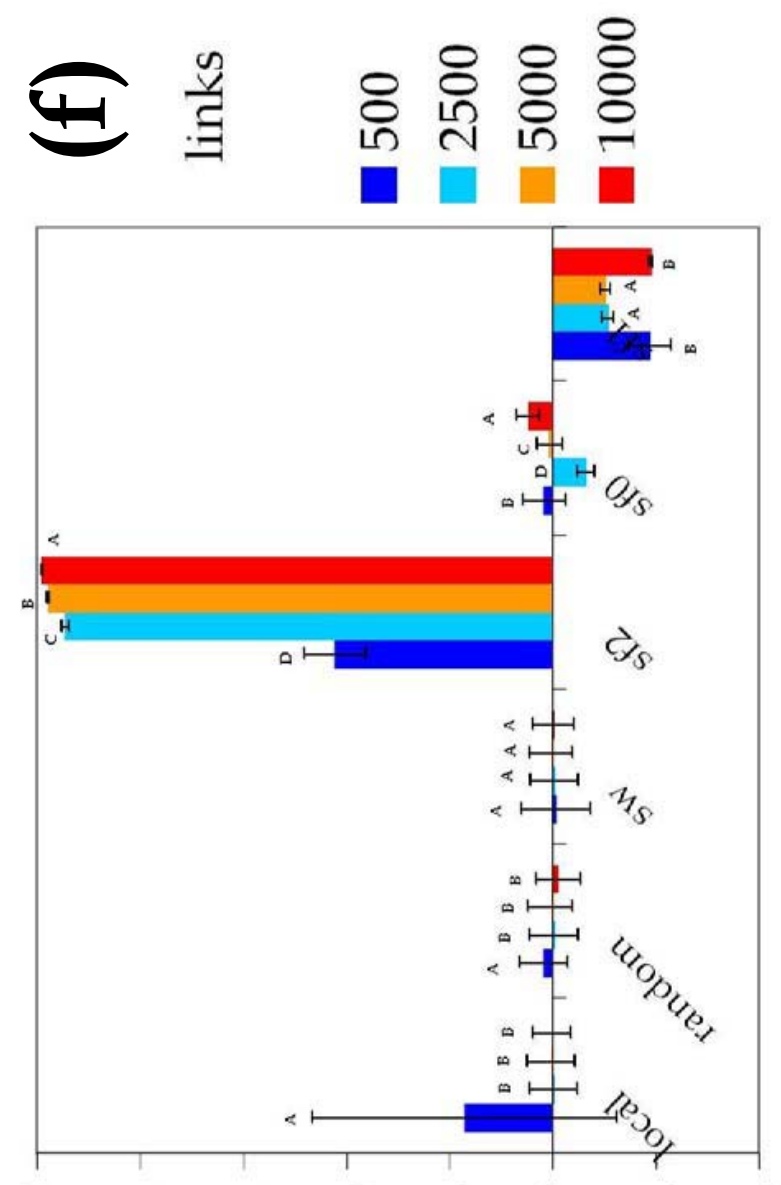

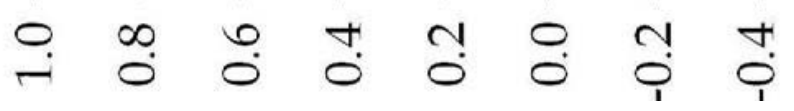

త
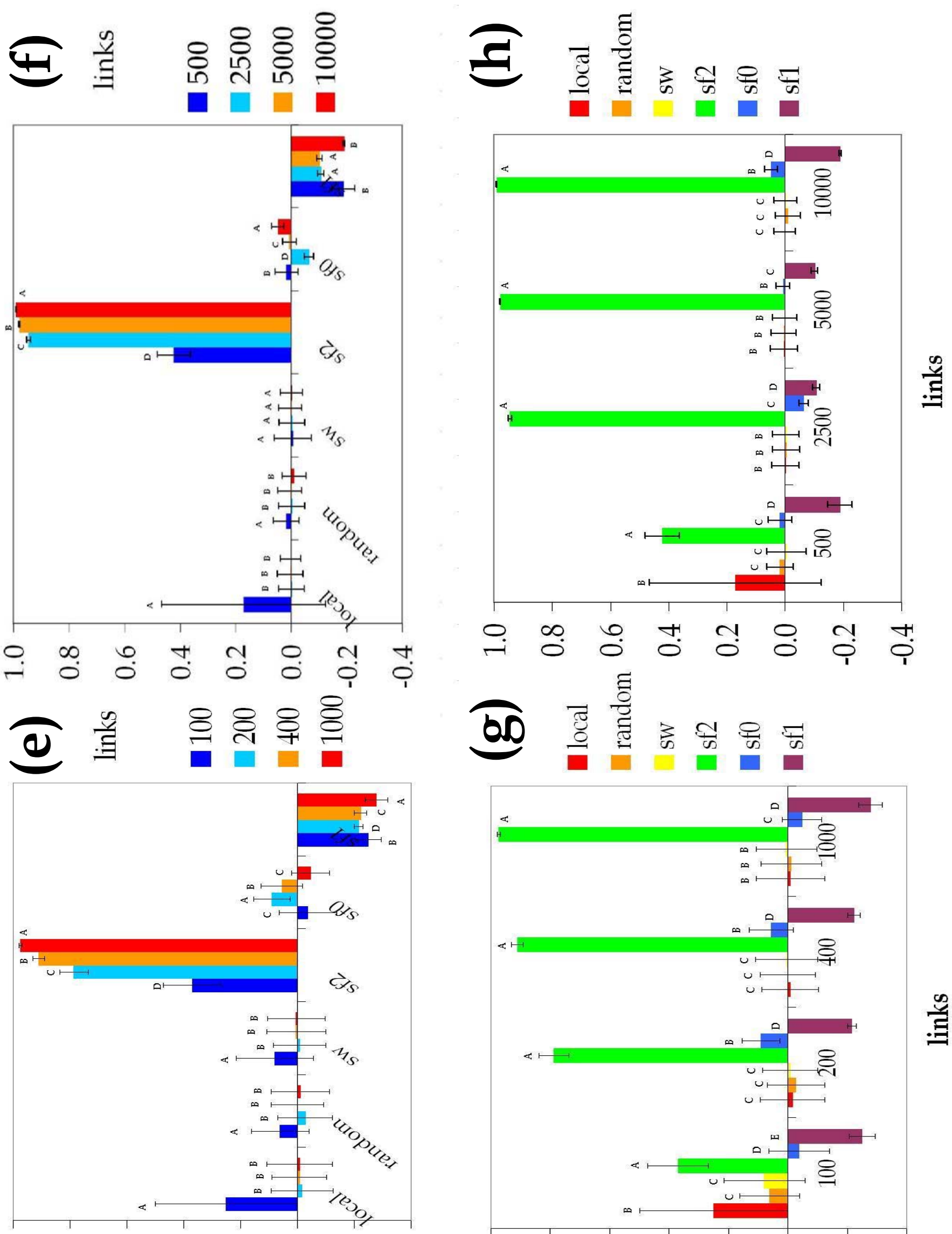

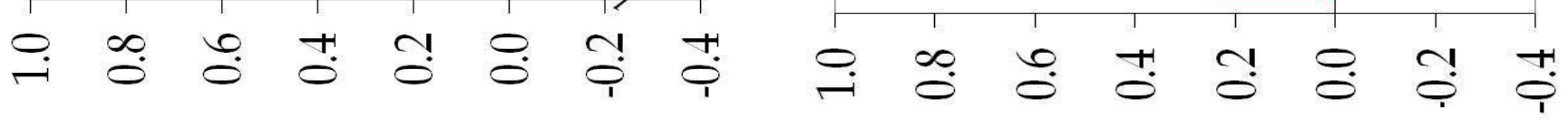

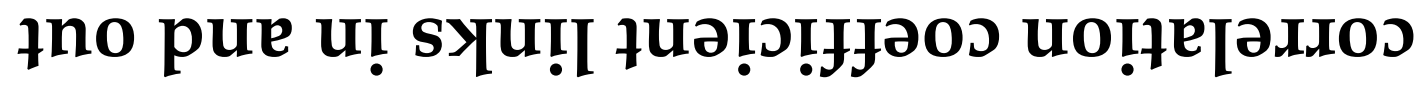




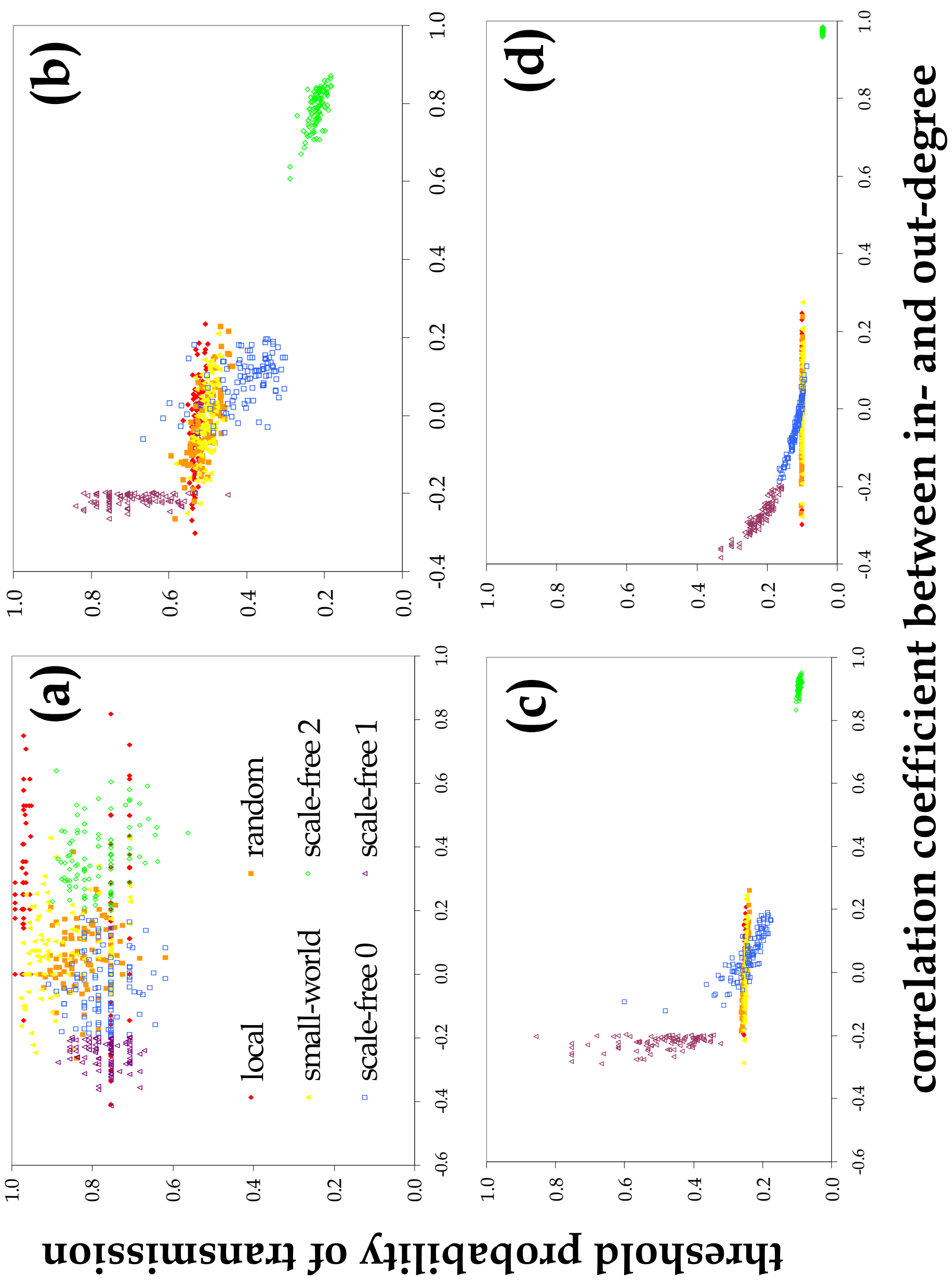




\section{ACCEPTED MANUSCRIPT}

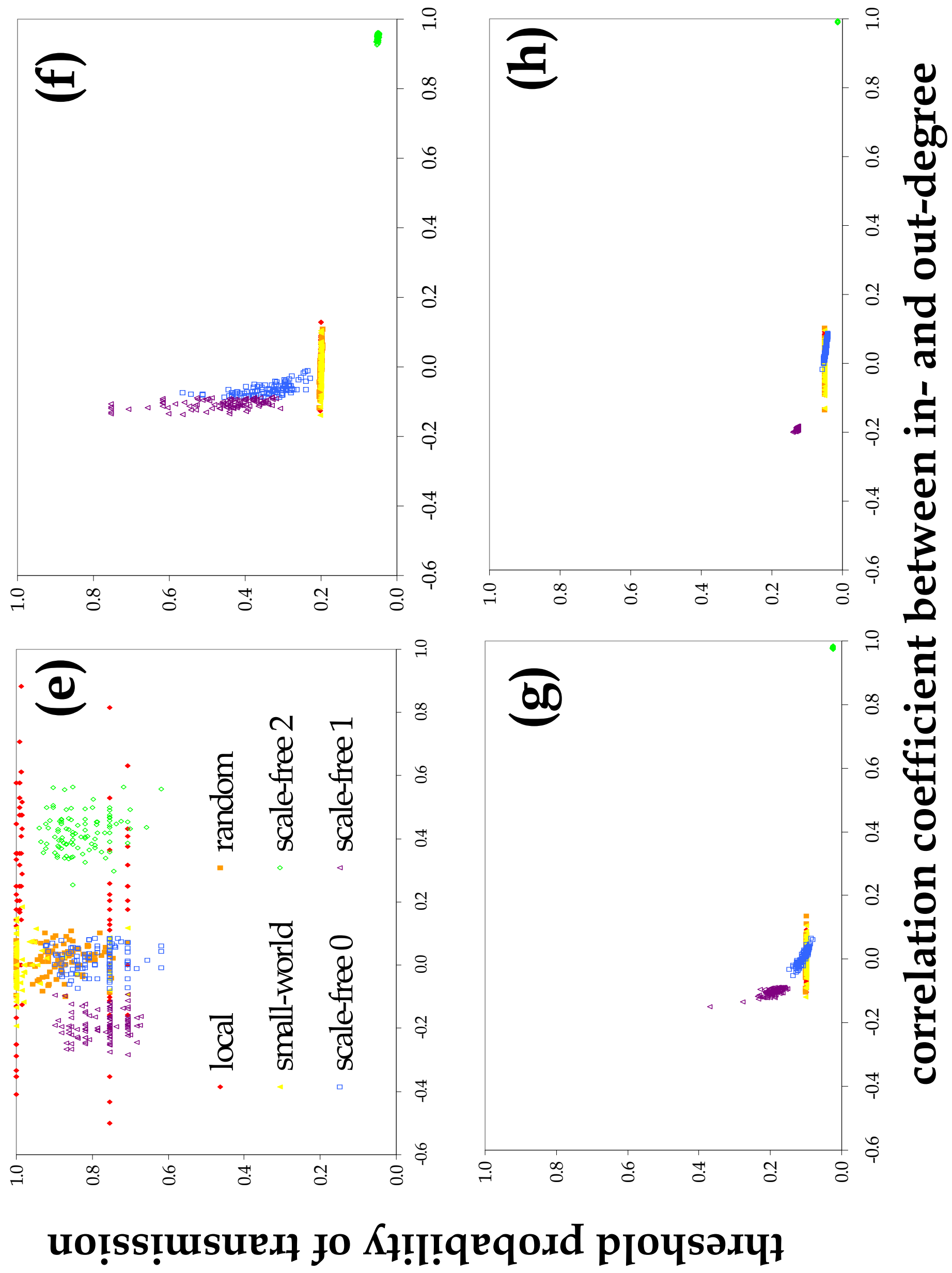




\section{ACCEPTED MANUSCRIPT}

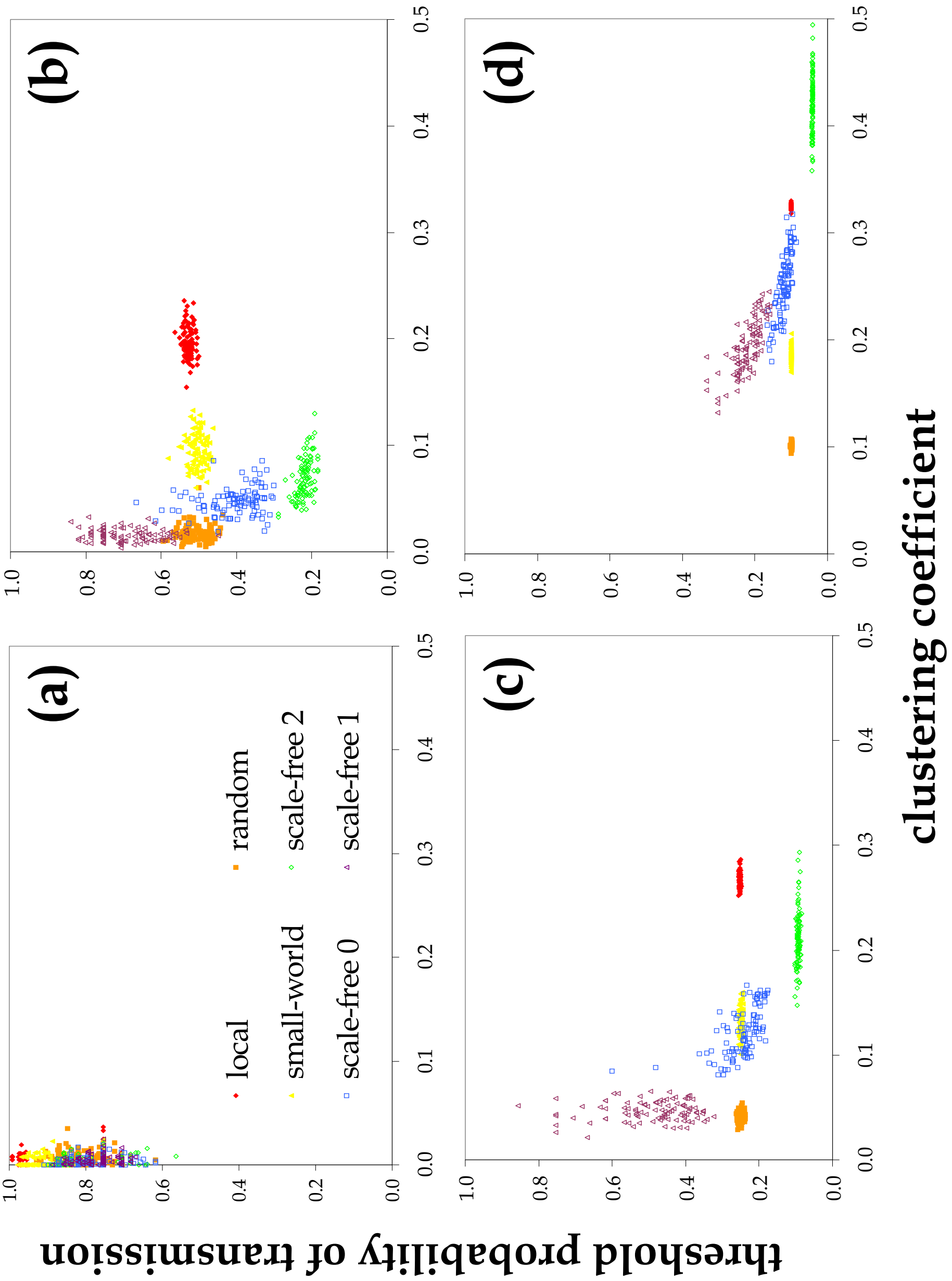




\section{ACCEPTED MANUSCRIPT}

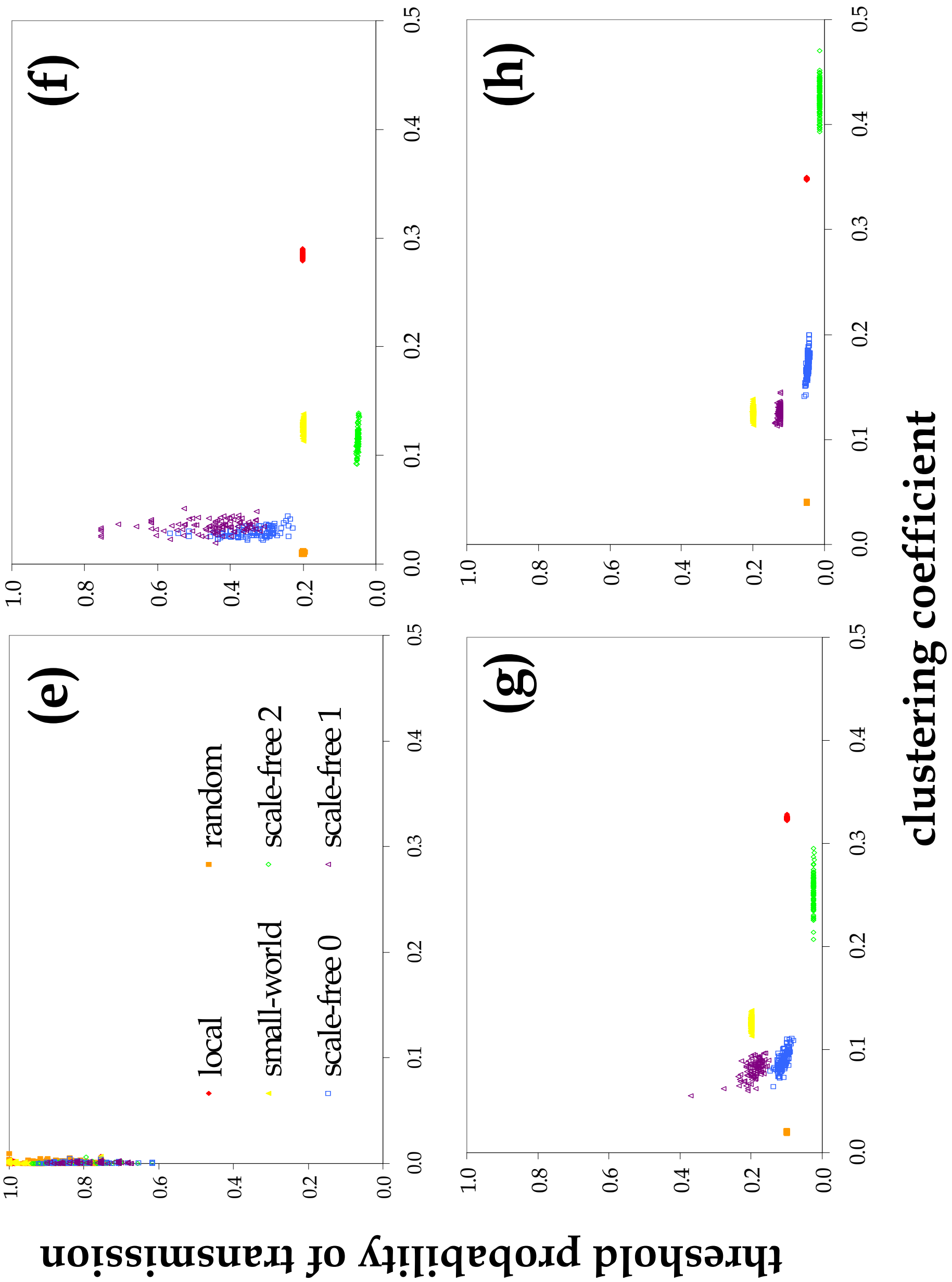




\section{ACCEPTED MANUSCRIPT}
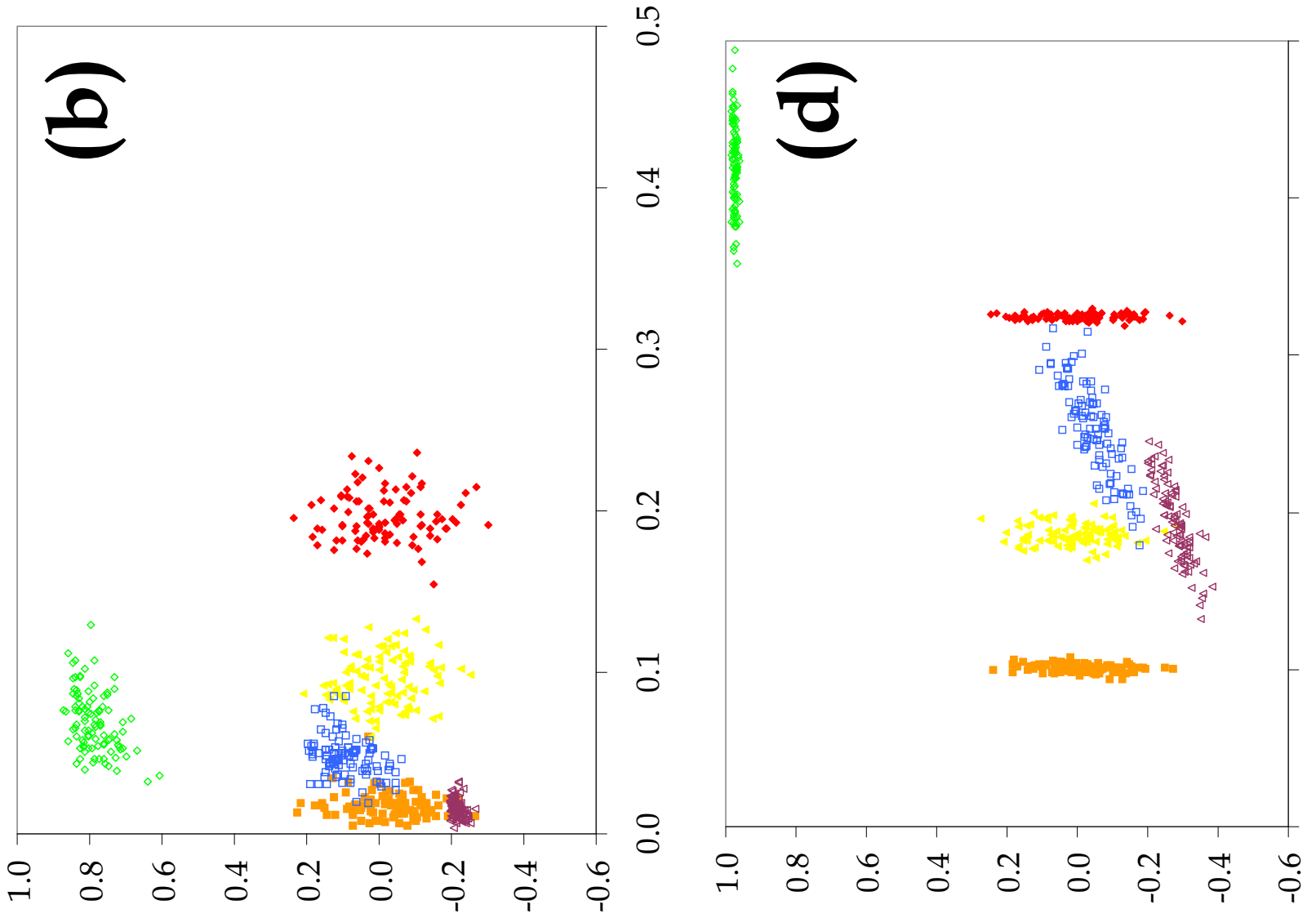

10

H.

3

ำ

뭉

a

कर

ำ

हृ

0

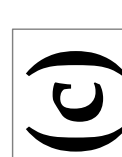

ำ

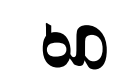

(

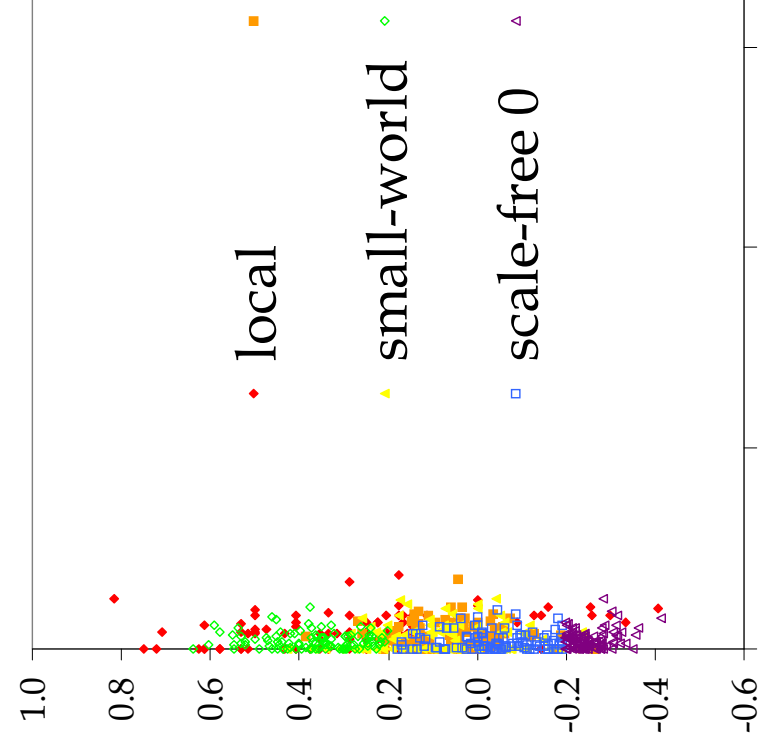

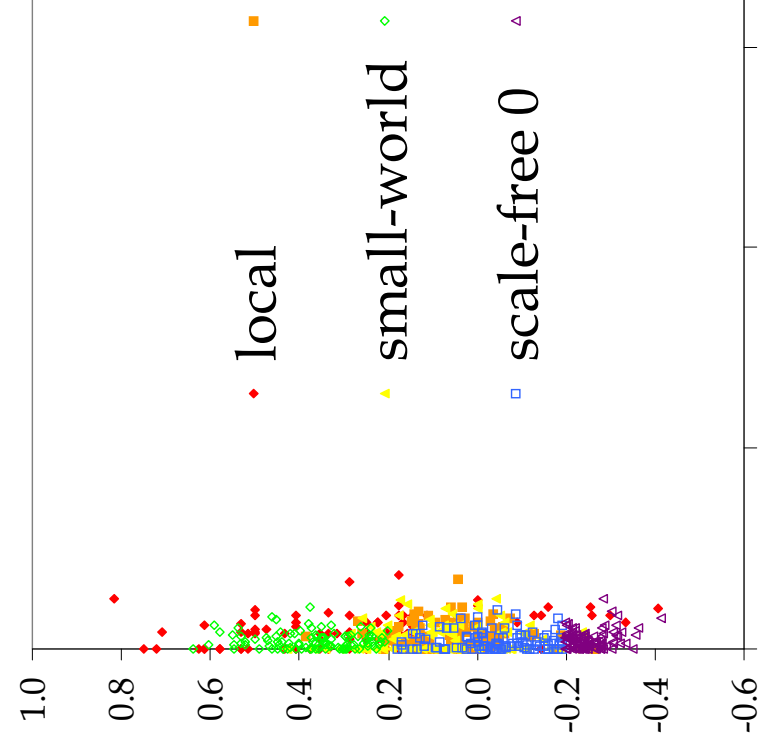
$+$ - ? 


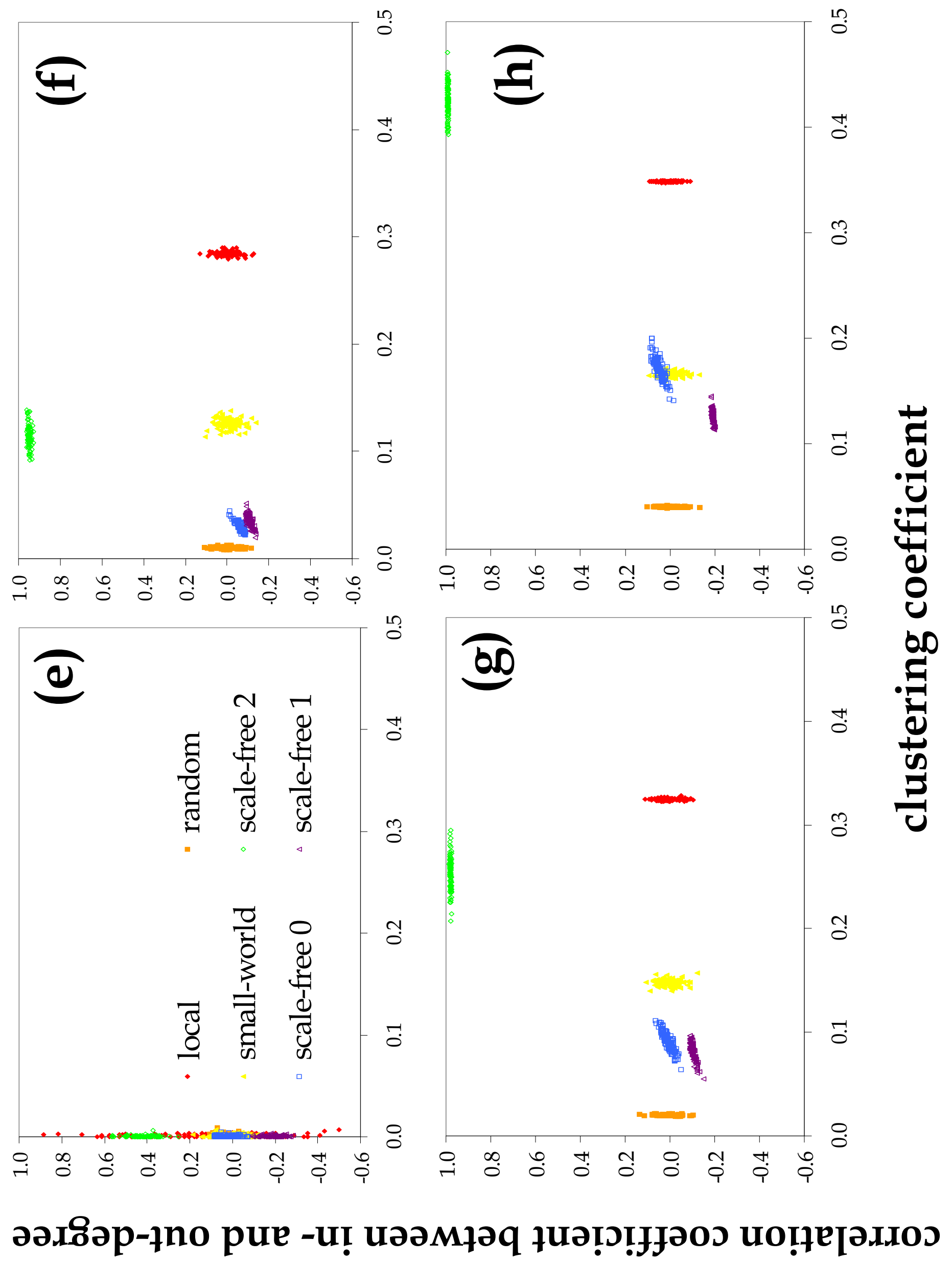

